\title{
A personagem e o espaço na ficção de Lygia Fagundes Telles
}

\author{
Character and space in the fiction of Lygia Fagundes Telles \\ El personaje y el espacio en la ficción de Lygia Fagundes Telles
}

Sayuri Grigório Matsuoka*

\section{Resumo}

Em mais de uma ocasião, Lygia Fagundes Telles recorre à figuração simbólica do espaço para instaurar um caráter insólito em suas narrativas. Em contos como "O encontro", "Venha ver o pôr do sol" e "A caçada", há sempre uma atmosfera de mistério e de apreensão que resulta da inter-relação entre personagem, espaço e linguagem. Em contos como esses, o leitor depara-se não só com a representação, mas com uma espécie de lente de aumento das possibilidades da ficção, em que imaginação, suspense e metaficção atravessam as narrativas. Este trabalho volta-se para esses temas, visitando as teorias narrativas, a filosofia e a crítica literária.

Palavras-chave: Lygia Fagundes Telles, mistério, personagens, espaço.

\section{Abstract}

On more than one occasion, Lygia Fagundes Telles has resorted to the symbolic figuration of space in order to set up an unusual mood in her narratives. In stories like "The meeting", "Come see the sunset" and "The hunt", there is always an atmosphere of mystery and apprehension which results from the inter-relation between character, space, and language. In stories like the aforementioned, the reader encounters not only the question of representation, but a sort of magnifying glass to the possibilities of fiction, in which imagination, suspense and metafiction traverse the narratives. This work returns to these themes, calling on theories of narrative, philosophy, and literary criticism.

Keywords: Lygia Fagundes Telles, mystery, characters, space.

\section{Resumen}

En más de una oportunidad, Lygia Fagundes Telles recurre a la figuración simbólica del espacio a fin de instaurar en sus narrativas un carácter insólito. En historias como "La reunión", "Vienen para ver la puesta del sol" y "la caza", hay siempre una atmósfera de misterio y aprehensión que resulta de la interrelación entre carácter, espacio y lengua. En historias como estas, el lector afronta no sólo la representación, sino una especie de lente de aumento de las posibilidades de la ficción, en el cual la imaginación, el suspenso y la metaficción cruzan las narrativas. Este trabajo trata estos temas, visitando las teorías narrativas, la filosofía, y la crítica literaria.

Palabras clave: Lygia Fagundes Telles, misterio, carácter, espacio.

Pode ser um bosque incrustado nas tramas de um tapete velho, um vale de montanhas cinzentas, uma rua deserta onde repousa uma árvore solitária ou um cemitério abandonado, toda narrativa iniciada com uma descrição de espaços como esses se assemelha a um convite, a uma porta se abrindo para um mundo estranhamente hospitaleiro. A estratégia é tão eficaz que as reações são imediatas: a curiosidade, a hesitação e o medo garantem as impressões de que falava Edgar Allan Poe em suas conhecidas resenhas sobre os Twice told tales, de Nathaniel Hawthorne. Os contos de mistério de Lygia Fagundes Telles têm este poder: conduzem o leitor, em meio a cenários enigmáticos, por estreitas vias entre o real e o irreal, a ponto de o familiar transformar-se inadvertidamente em estranho.

\footnotetext{
* Doutora em literatura comparada e professora da Universidade Estadual do Ceará (UECE), Fortaleza, CE, Brasil. Dorcid.org/0000-0002-8828-2625. E-mail: sayurigmb@gmail.com
} 
A exemplo de escritores e escritoras latino-americanos do século XX, Lygia Fagundes Telles desenvolve uma poética em que a realidade assume despretensiosamente uma feição insólita, sem, entretanto, incorrer no sobrenatural. Não raro, seus relatos tornam-se arena de embate entre memória e ficção, assinalando um tenro simbolismo dos objetos que alude a uma apreensão mítica do mundo. Na mesma medida, essa realidade promove uma percepção ampliada das coisas, em que a forte presença da consciência do ato ficcional sempre possibilita uma interpretação metaficcional do relato. Esse caminho configura-se de um modo aparentemente simples, o que favorece a descoberta da condição de artefato da narrativa, sempre com vistas a suscitar questionamentos acerca da relação entre realidade e ficção. A técnica para criar essa impressão consiste, muitas vezes, em situar as personagens em uma atmosfera de suspense.

O espaço é, nesse sentido, um elemento essencial não só para a estruturação da narrativa ficcional, mas para a recepção. Em muitos casos, ele tende a se configurar pela referência à toponímia real, o que permite a aproximação imediata entre ficção e realidade, mas sua atuação vai além da localização e da figuração geográficas, estando muitas vezes relacionado a significados simbólicos e ideológicos que remetem a experiências de naturezas diversas. Participa efetivamente da consolidação de todo relato, mas, em estórias de mistérios, sua concepção parece assegurar a premissa do gênero em aproximar os diferentes efeitos impressivos da realidade. Isto o alinha com a perspectiva das personagens. Assim é com a personagem narradora de "O encontro", com Ricardo e Raquel, personagens de "Venha ver o pôr do sol", com as amigas de "As formigas". Nesses contos, os espaços impõem um certo apelo dramático, cuja relação se dá pela influência direta na ação, não necessariamente por uma intervenção determinista do meio sobre as personagens, mas por uma figuração física, psicológico-social ou cognitiva destas, que afeta diretamente o leitor.

No século XX, Genette sugeria essa especificidade, indagando sobre a existência de uma "espacialidade literária ativa e não passiva, significante e não significada, própria da literatura, específica da literatura, uma espacialidade representativa e não representada?" (Genette, 1972, p.105). Genette insinuava, assim, que a importância da consciência do caráter linguístico dessa especificidade talvez fosse o ponto mais importante para a observação das constituições semânticas próprias do espaço no texto literário. Nesse sentido, consideram-se os mecanismos da efetivação cognitiva da leitura para a construção dos significados e para aspectos ligados às respostas do leitor às provocações da narrativa. A antecipação dessas reações e a consciência do seu papel na percepção das mensagens deixadas ao longo da estória são os principais agentes das unidades de efeito da ação. Essas estratégias direcionam para a personagem as condições favoráveis à instauração de uma empatia com o leitor. Assim, a personagem orienta o narratário em meio à dispersão de dados distribuídos ao longo da narrativa, estabelecendo com ele uma identificação fundamental para as impressões vindas do texto. A construção da personagem, desse modo, é fundamental para esse aspecto do enredo, pois sua caracterização e ações suscitam o processamento cognitivo necessário para a geração de imagens relevantes às inferências esperadas do leitor (Weststeijn, 2010/2011).

Essa compreensão ontológica de uma categoria constituída linguisticamente dá-se pelo viés semiótico que recruta conhecimentos das mais diversas ordens. É a linguagem que orienta essa representação na medida em que promove os níveis de apreensão dos objetos pela consciência, processo em que o leitor entende a personagem como forma representativa de dramas humanos, principalmente por sua identificação imediata com ela. O espaço, nesse sentido, unese à personagem para elaborar a perspectiva e o sentido do mistério que, na obra de Lygia, determinam uma percepção intuitiva da realidade. Essa relação subjetiva com o espaço é uma das formas de acesso à referida empatia do leitor com a personagem, na medida em que esta "é normalmente o eixo em torno do qual se organiza a economia do relato" (Reis, 2003, p. 360).

Esse tipo de artifício produz um efeito específico no público, de modo que o espaço, a personagem e a maneira como eles se entrelaçam modulam a recepção do leitor, conduzindo-a ao estranhamento. O primeiro escritor a salientar a importância desses efeitos foi Edgar Allan Poe. Na Filosofia da composição (1846) e nas resenhas sobre os Twice-told tales (1842), de Nathaniel Hawthorne, Poe evidencia a figura do leitor no processo narrativo, principalmente ao mostrar a 
influência de suas reações para a obtenção de certos impactos da leitura. O processamento do evento insólito deve muito ao acordo tácito entre leitor e personagem. Da cumplicidade entre ambos é que medo, tensão, suspense, terror e todos os outros efeitos dos gêneros que exploram o suspense acontecerão. É a partir dessa adjacência entre sentimentos e ficção que as personagens se materializam no campo perceptivo do leitor. Sua realização está subordinada a processos de ancoragens, como estratégias de efeitos de real, descrição de características físicas, do ambiente que a cerca, de suas ações e dos pensamentos que são a elas atribuídos. Nesse sentido, elas são um constructo semiótico, e é o ato definido cultural e socialmente de contar histórias ficcionais que as constitui e define (Margolin, 2009, p. 67).

Em obras cujo espaço atua de modo simbólico, conferindo uma a-historicidade ao relato e à existência das personagens, essa identificação orgânica entre um e outro é ainda mais visível. São lugares que, em uma perspectiva filosófica, podem ser vistos e interpretados como "espécies de utopias efetivamente realizadas nas quais todos os outros posicionamentos reais que se podem encontrar no interior da cultura estão ao mesmo tempo representados, contestados e invertidos" (Foucault, 2001, p. 415). São lugares que existem de fato e são, portanto, perfeitamente reconhecíveis por qualquer leitor. Entretanto, sua fisionomia conduz a uma observação do real e do irreal, da presença e da ausência, ao mesmo tempo. No caso da narrativa ficcional, impressões como essas são determinantes para a forma como o espaço é internalizado pela personagem ou para o modo como ela reflete uma parte significativa de sua constituição existencial que se espelha na humanidade. Entendidos como "heterotopias" por Foucault, esses lugares situam-se no limiar entre real e irreal porque, por um lado, criam "um espaço de ilusão que denuncia como mais ilusório ainda qualquer espaço real, todos os posicionamentos no interior dos quais a vida humana é compartimentalizada" (Foucault, 2001, p. 420), e, por outro, podem ainda criar um espaço de compensação e não de ilusão.

Assim, esse tipo de espaço figura na narrativa como elo entre a ação da personagem e a decodificação que o leitor fará de determinados propósitos subjacentes às suas ações. Um exemplo muito claro dessa imbricação é a caracterização do local de encontro dos exnamorados Raquel e Ricardo, de "Venha ver o pôr do sol". Para além da ironia marcada pelo traço hiperbólico na designação do local do encontro - um cemitério abandonado, onde não restam nem vivos nem mortos (Telles, 1998) -, essa equivalência entre personagem e ambiente não é condicionada por fenômenos físicos, geográficos ou por características fisiológicas, como quer o determinismo do século XIX; revela, por outro lado, o desamparo universal do ser a partir de uma focalização trágica do espaço. É este que possibilita a estruturação do jogo narrativo que conduz a ação da personagem Ricardo e sua movimentação na diegese. Essa interação entre personagem e espaço na obra de Lygia reflete ainda, tal como observa Regina Dalcastagnè, a angustiante posição feminina em situações de claustrofobia emocional: "Suas protagonistas, de um modo geral, são mulheres sufocadas pelas exigências sociais, pelos compromissos familiares, pelas máscaras que já não descolam do rosto. Daí confiná-las numa casa, para fazer ressoar seu confinamento interno" (Dalcastagnè, 2003, p. 22). No caso de "Venha ver o pôr-do-sol", a situação de aprisionamento é levada ao extremo: Raquel é encarcerada pelo ex-namorado no subsolo do cemitério desativado.

A degradação do ambiente permite ao leitor também uma observação dos processos mentais atribuídos às personagens. Nesse sentido psicológico, o cemitério representa uma face de seu comportamento que é a deterioração de seus sentimentos e a confusão mental a qual a frustração pode levá-las. Deve-se, nessa apreciação da personagem, considerar a virtualidade da sua existência e o caráter abstrato de sua constituição psíquica e sociocultural. No conto, tanto Raquel como Ricardo são vistos pela narradora como pessoas complexas, ela pela superficialidade e prepotência, ele pela obsessão por vingança e pela dissimulação - 0 que acaba por se confirmar na ação, com a incapacidade de Raquel de perceber sua vulnerabilidade e se deixar conduzir ao cárcere que provocará sua morte e com a participação de Ricardo na arquitetura dessa armadilha.

As representações simbólicas do espaço, tal como se vê no conto, valorizam ainda sua perspectiva estética e lhe dão um sentido atemporal. O tempo aparece nessa concepção como 
um elemento intrínseco à categoria de espaço, pois é ele que permite a união com o verdadeiro mundo no qual os eventos ocorrem na medida em que é a condição do fluxo desta mudança (Frank, 1991, p. 650). Se o tempo, entendido em uma concepção cronológica, é apreendido linearmente, nas narrativas de mistérios de Lygia Fagundes Telles essa limitação é ignorada, pois sua observação dá-se, muitas vezes, pela contemplação dos ambientes. É nesse sentido que a percepção do espaço e, consequentemente, a do tempo, aqui se faz de modo cada vez mais subjetivo, principalmente porque há, nessa figuração espacial, reflexões acerca do envelhecimento, da morte ou de perdas irrecuperáveis que estão diretamente ligadas a essas duas instâncias. Essa representação do espaço pelo subjetivismo manifesta-se notadamente em situações de deslocamentos, quando a alusão aos lugares se dá sem coordenadas explícitas. Pensar a inserção de uma personagem em determinados contextos espaciais é também pensar a noção de identidade presente nesse reconhecimento.

Considerando o encontro fortuito entre objetivação e subjetivação, entre realidade e ficção, ou ainda, entre realidade e imaginação, pode-se perceber no procedimento artístico de Lygia Fagundes Telles uma síntese entre essas três instâncias. Principalmente porque a observação desse movimento dialético entre objeto e sujeito, ou entre espaço e personagem, evidencia a falibilidade de uma percepção unilateral da realidade. Em muitos aspectos, essa visão se aproxima do que escritores como Franz Roh entendem por realismo mágico: um tipo de narrativa que surge de uma tensão incessante entre a submissão ao mundo presente e a vontade construtiva frente a ele (Roh, 1995, p. 52), em que a finalidade material pode ser perfeitamente substituída por outras magnitudes que permitem a colaboração contínua entre essas duas esferas da percepção humana. A apreensão mágica da realidade resultaria desse confronto de realidades ou da aceitação da existência de realidades coexistentes.

Em uma perspectiva ontológica, de correspondência direta entre personagem e serhumano, essa postura se estende ao questionamento das ações no mundo; no universo ficcional, a caracterização metanarrativa conduz a uma questão sempre presente nos contos e nos romances de Lygia: a tenuidade da linha que separa realidade e ficção. Como se a ficção fosse uma via para uma percepção que escapa ao imediato e ao óbvio. Nesse sentido, o insólito configura-se como a expressão desses aspectos reprimidos pela razão, pelo medo, pelo terror e até pela razoabilidade. Em sua monografia dentro da monografia, como chama seu trabalho sobre o espaço narrativo, inserido no contexto de seu livro sobre o espaço no romance de Lima Barreto, Osman Lins chama a atenção para a dinâmica imprevisível e imprescindível desta categoria para os efeitos da ação em obras de natureza fantástica, como resultado de ambientações onde espelhos, labirintos, jardins mágicos (Lins, 1976, p. 66) designam uma atmosfera mítica. É o que sugere a alegorização dos sentimentos das personagens como bens perdidos no cemitério de "Venha ver o pôr do sol".

Essa aproximação do realismo mágico, do fantástico ou do insólito não impede que os recursos metaficcionais dos textos de Lygia surjam de modo a contestar as apreensões convencionais da realidade. Eles aparecem de um modo muito explícito na leitura feita por Lygia do conto "Missa do Galo", de Machado de Assis, em que uma narradora inconformada, tenta reacender das brasas o fogo de uma paixão sonegada. Pela maneira como Linda Hutcheon (1984, p. 12) a define, metaficção é a "ficção sobre a ficção", o que surge no âmbito ficcional sob forma de comentário e que revela sua identidade narrativa e/ou linguística. Noutras palavras, enredam-se à ficção, paralelamente, informações, comentários, estórias, que evidenciam o próprio ato ficcional. Lygia expõe essa consciência do processo textual em "Variação sobre o mesmo tema", alinhavando a sua estória na estória de Machado. Convida o leitor a participar de sua indiscrição quando entra no espaço da narrativa machadiana para perscrutar-lhe os meandros omitidos no texto que a inspirou.

No trabalho de Telles, as personagens, o enredo, as circunstâncias e o espaço do texto-fonte reaparecem sob a perspectiva de uma narradora explicitando seu processo de criação. Ela observa o espaço, descreve e comenta as ações das personagens, indicando sempre, por referências literais, o texto que observa, confrontando Nogueira, o narrador de Machado, levantando suspeitas sobre sua credibilidade, evidenciando o processo ficcional e solicitando ao 
leitor que reconstrua a história inteira, fazendo, por vezes, esse próprio papel: "vou recomeçar, ainda continuo na rua, bafejando na vidraça da noite antiquíssima. Sinto mais agudo o desejo de entrar na casa e abrir caixas, envelopes, portas!" (Telles, 1977, p. 99). O olhar da narradora bisbilhota, cascavilha avidamente cada canto da casa-conto em busca de pistas do enlace-texto entre o jovem Nogueira e Conceição. Eis que o espaço narrado é o próprio espaço ficcional, espaço onde lugares, coisas e pessoas assumem explicitamente formas literárias.

O processo da escrita, no entanto, traz sentimentos que possibilitam aflorar na consciência da narradora questionamentos acerca da natureza das declarações do narrador do texto-fonte. E, durante a elaboração de seu texto, a casa e a situação fazem-se mais presentes, acompanhando todo seu processo criativo. A narrativa engendra um passado. Nesse sentido, os objetos e sua disposição na casa funcionam como uma ponte entre o real e a ficção, relevando esta última como meio de percepção de uma realidade mais abrangente. Em outras palavras: metaforizam a ideia de narrativa ficcional através da descrição do espaço. Nos dois casos, a identificação das personagens ao espaço parece ser uma estratégia definitiva para a obtenção dos efeitos impressivos do leitor. Principalmente por evidenciar uma compreensão identitária da personagem com o ambiente e representar os sentimentos humanos, refletindo simbolicamente os estados de seus ânimos que formam com o esquema linguístico da obra um complexo discursivo que permite ao leitor inferir determinadas noções de sentimentos como medo e sedução. A sensação insólita nasce dessa perspectiva, principalmente por se tratar de um artifício diretamente relacionado às desautomatizações da linguagem.

A trama de "A caçada" também sugere essa forma de apreensão de um espaço aparentemente comum, tão real quanto qualquer outro presente em cidades como São Paulo. A loja de antiguidades é mostrada ao leitor de modo a conduzi-lo a um cômodo, este sim, nada ordinário. O tapete no fundo da loja converte-se, perante os olhos do homem, em um cenário de caçada. É a dinâmica da caracterização do bosque que possibilita à personagem as experiências mentais e as dúvidas sobre o desempenho do seu papel na estória, transpondo-o do familiar ao estranho, aos lugares recônditos da cidade que resguardam uma atmosfera de isolamento. Até mesmo em uma grande metrópole como São Paulo, onde grandes massas de pessoas deslocam-se ininterruptamente, igrejas e cemitérios, por exemplo, têm o poder de suspender o tempo e provocar a sensação de incerteza.

Essa ordenação dos acontecimentos promove reações que, segundo as formulações psicanalíticas freudianas, remetem a uma concepção animista do universo, a um tempo remoto quando a supervalorização dos processos mentais conduzia o comportamento humano. Esse homem primitivo não distinguia realidades. Espíritos e pessoas vivas apresentavam-se a ele de maneira igual. À medida que esse comportamento foi superado, perdeu-se esse sentimento mágico das coisas. No entanto, a evolução natural não permitiu esse afastamento sem que traços dessa condição fossem totalmente suprimidos do intelecto - e são justamente esses resíduos que afloram quando uma narrativa conduz o leitor do familiar ao estranho (Freud, 1976). O medo e o terror dessa nova perspectiva vêm justamente do terreno desconhecido, onde as certezas são postas em cheque e a iminência do perigo devolve a consciência da vulnerabilidade.

A inscrição do espaço textual metaforizado no tapete que, em seguida, toma o contorno de um bosque e depois de um espaço que envolve e orienta a dinâmica psicológica e física da personagem, assume um caráter simbólico em que a simbiose entre essas duas categorias narrativas evidencia-se a cada sequência do conto. O leitor acompanha a cooptação dessa personagem pelo espaço imaginado e percebe a partir dessa integração a função deste no entrecho, um espaço que se distingue das coordenadas usuais para gradualmente transformar-se em reflexo do ato ficcional.

A análise dos contos aqui mencionados tentou mostrar a simbiose entre personagem e espaço e a importância dessa relação para a recepção dos textos de mistérios de Lygia Fagundes Telles. Buscou-se observar o espaço como sustentáculo da construção da personagem, e a leitura insólita que resulta desse entrelaçamento, ao revelar os lugares muitas vezes como exteriorização dos conflitos psicológicos figurados nas narrativas; procedimentos em que os ambientes materializam os medos, as angústias e os infortúnios desses heróis, figurativizando 
paisagens que revelam a dimensão mítica de suas experiências e proporcionando ideias, vagas ou amplas, de lugares que envolvem o leitor e o transportam para o mundo ficcional.

A tradição racionalista mostra que a consciência se acomoda facilmente aos critérios de estabilidade: opta-se por assimilar e aceitar como realidade o que dá a sensação de conforto e segurança e se ignora o que ameaça esses estados. Na tentativa de mostrar, no âmbito literário, esses medos, as narrativas de Lygia Fagundes Telles questionam as conveniências do mundo através da linguagem. Há, segundo essa visão, uma técnica importante que expõe as idiossincrasias de personagens, representantes de homens e de mulheres que reconhecem a influência da imaginação, da poesia e do sonho em suas existências.

\section{Referências}

DALCASTAGNÈ, Regina (2003). Sombras da cidade: o espaço na narrativa brasileira contemporânea. Estudos de literatura brasileira contemporânea, Brasília, n. 21, p. 33-53, jan./jun.

FOUCAULT, Michel (2001). Outros espaços. In: FOUCAULT, Michel. Ditos e escritos III. Rio de Janeiro: Forense Universitária. p. 411-422.

FRANK, Joseph (1991). Spatial Form in modern literature: an essay in three parts. The Sewanee Review, Sewanee, v. 53, n. 4, p. 433-456.

FREUD, Sigmund (1976). O estranho. In: FREUD, Sigmund. Edição standard brasileira das Obras Psicológicas Completas de Sigmund Freud. Rio de Janeiro: Imago. v. XVII.

GENETTE, Gérard (1972). Figuras. São Paulo: Perspectiva.

HUTCHEON, Linda (1984). Narcisistic narrative: the metaficcional paradoxe. New York: Methuen.

LINS, Osman (1976). Lima Barreto e o espaço romanesco. São Paulo: Ática.

MARGOLIN, Uri (2009). Character. In: HERMAN, David (Org.). The Cambridge companion to narrative. Cambridge: Cambridge University Press.

POE, Edgar Allan (2003a). Review of Twice-Told Tales. In: POE, Edgar Allan. The Fall of the House of Usher and other writings. London: Penguin Books. p. 387-398.

POE, Edgar Allan (2003b). The philosophy of composition. In: POE, Edgar Allan. The Fall of the House of Usher and other writings. London: Penguin Books. p. 430-442.

REIS, Carlos (2003). O conhecimento da literatura. Introdução aos Estudos Literários. 2. ed. Coimbra: Almedina.

ROH, Franz (1995). Magic realism: post-expressionism (1925). New York: Routledge.

TELLES, Lygia Fagundes (1981). Mistérios. Rio de Janeiro: Rocco.

TELLES, Lygia Fagundes Telles (1977). Missa do Galo. In: ASSIS, Machado de et al. Missa do Galo de Machado de Assis: variações sobre o mesmo tema. São Paulo: Summus, p. 99-109.

WESTSTEIJN, Willem G. (2010/2011) Towards a Cognitive Theory of Character. Amsterdam International Electronic Journal for Cultural Narratology, Amsterdam, n. 6, p. 53-66, Autumn. 